Jurnal Media Agribisnis Vol. 4 No. 1 Tahun 2019 Hal 28 - 33

Media Komunikasi Hasil Penelitian Bidang Ilmu Agribisnis

ISSN print 2548-7027

ISSN online 2541-6898

\title{
SALURAN DAN MARJIN TATANIAGA KOPI DI DESA MEKAR JAYA KECAMATAN BETARA KABUPATEN TANJUNG JABUNG BARAT
}

\author{
${ }^{1)}$ Siti Abir Wulandari dan ${ }^{2)}$ Karmayanto \\ ${ }^{1)}$ Program StudiAgribisnis, Fakultas Pertanian Universitas Batanghari \\ ${ }^{2)}$ AlumniProgram StudiAgribisnis, Fakultas Pertanian Universitas Batanghari \\ Jl. SlametRiyadi-Broni, Jambi. 36122. Telp. +6274160103 \\ ${ }^{1)}$ email korespondesi : siti.abir.wulandari@unbari.ac.id
}

\begin{abstract}
Coffee production in Jambi Province in 2017 was 13,636 tons with an average productivity of 0.5 tons/ha. Coffee production in Tanjung Jabung Barat Regency amounted to 1,081 tons with an average productivity of 0.4 tons/ha. Betara District produces coffee of 594 tons with productivity of 0.4 tons/ha. Mekar Jaya Village has the largest planting area of 399 ha with a production of 133 tons and productivity of 0.33 tons / ha. This high coffee production, especially when viewed from the benefits received by farmers, does not reflect the efficiency of the marketing system. Farmers do not have the power to determine prices to consumers. The purpose of this study is to identify the trading channe and determine the coffee trading margin. This research was conducted in Mekar Jaya Village, Betara District, Tanjung Jabung Barat Regency. Sampling was done by survey method and Snowball sampling, analyzed descriptively both qualitatively and quantitatively. The results showed that there was 1 coffee trading channel pattern with an average trading margin between farmers and collectors of Rp. $3000 / \mathrm{kg}$, while the average margin between collectors and collectors is Rp. $5000 / \mathrm{kg}$. The total trading margin of the farmers' trading margins with collectors, collectors and collectors is Rp. $8000 / \mathrm{kg}$.
\end{abstract}

Keywords: Coffee, marketing, merchantman

\section{Abstrak}

Produksi kopi di Provinsi Jambi pada tahun 2017 adalah 13.636 ton dengan produktivitas rata-rata 0,5 ton/ha. Produksi kopi di Kabupaten Tanjung Jabung Barat sebanyak 1.081 ton dengan produktivitas rata-rata 0,4 ton/ha. Kabupaten Betara menghasilkan kopi 594 ton dengan produktivitas 0,4 ton/ha. Desa Mekar Jaya memiliki luas tanam terbesar yaitu sebsar 399 ha dengan produksi 333 ton dan produkstivitas 0,33 ton/ha. Tingginya produksi kopi ini terutama bila dilihat dari keuntungan yang diterima petani belum mencerminkan efisiensi sistem pemasaran. Petani tidak memiliki kekuatan dalam menentukan harga kepada konsumen. Tujuan dari penelitian ini adalah untuk mengidentifikasi saluran tataniaga dan menentukan marjin tataniaga kopi.Penelitian ini dilakukan di Desa Mekar Jaya Kecamatan Betara Kabupaten Tanjung Jabung Barat. Pengambilan sampel dilakukan dengan metode survey dan Snowball sampling, dianalisis secara deskriptif baik kualitatif maupun kuantitatif. Hasil penelitian menunjukkan terdapat 1 pola saluran tataniaga kopi dengan rata-rata margin tataniaga antara petani dengan pengumpul sebesar Rp. 3000/kg, sedangkan margin rata-rata antara pengumpul dengan pengumpul sebesar Rp. 5000/kg. Margin tataniaga total dari

Diterbitkan oleh Program Studi Agribisnis Fakultas Pertanian Universitas Batanghari Jambi Halaman 28 
Jurnal Media Agribisnis Vol. 4 No. 1 Tahun 2019 Hal 28 - 33

Media Komunikasi Hasil Penelitian Bidang Ilmu Agribisnis

ISSN print 2548-7027

ISSN online 2541-6898

margin tataniaga petani dengan pengumpul, pengumpul dengan pengumpul sebesar adalah Rp. 8000/kg.

Kata Kunci: Kopi, pemasaran, lembaga tataniaga

\section{PENDAHULUAN}

Komoditas perkebunan merupakan andalan bagi pendapatan nasional dan devisa negara Indonesia. Kopi merupakan salah satu komoditi perkebunan yang memberikan kontribusi besar di Indonesia. Luas areal kopi di Indonesia pada tahun 2017 sebesar 1.227.787 ha dan produksi kopi sebesar 637.539 ton. (Direktorat Jendral Perkebunan, 2018). Produksi kopi Provinsi Jambi pada tahun 2017 sebesar 13.636 ton dari 26.646 ha luas areal kopi dengan produktivitas ratarata sebesar 0.5 ton/ha (Direktorat Jendral Perkebunan, 2018). Produksi kopi yang dihasilkan dari Kabupaten Tanjung Jabung Barat pada tahun 2017 sebesar 1.081 ton dengan luas tanam sebesar 2.610 ha dengan produktivitas rata-rata sebesar 0.4 ton/ha (Jambi dalam angka, 2018).

Produksi kopi terbesar berada di Kecamatan Betara yaitu sebesar 594 Ton dari 1.492 ha luas lahan dengan produktivitas sebesar 0,4 Ton/ha. Produktivitas ini masih berada di atas rata-rata produktivitas kecamatan sebesar 0,39 ton/ha. (Kabupaten Tanjung Jabung Barat dalam angka, 2018). Desa Mekar Jaya merupakan desa yang mempunyai luas tanam terbesar yaitu sebesar 399 ha dengan produksi sebesar 133 ton dan produktivitas sebesar 0,33 ton/ha (Kecamatan Betara dalam angka, 2018).

Tingginya produksi yang dihasilkan petani tidaklah berarti jika tidak diiringi dengan biaya yang rendah di tingkat petani, informasi pasar tentang kualitas yang diinginkan oleh pasar serta jalan tataniaga yang harus dilalui oleh kopi itu sendiri. Tingginya produksi kopi ini terutama bila dilihat dari keuntungan yang diterima petani belum mencerminkan sistem pemasaran yang efisien. Petani tidak memiliki kekuatan dalam menentukan harga kepada konsumen. Oleh sebab itu peneliti tertarik untuk melakukan penelitian dengan judul Saluran Dan Marjin Tataniaga Kopi Di Desa Mekar Jaya Kecamatan Betara Kabupaten Tanjung Jabung Barat. Penelitian ini bertujuan untuk mengidentifikasi saluran dan menghitung marjin tataniaga kopi di Desa Mekar Jaya Kecamatan Betara Kabupaten Tanjung Jabung Barat Propinsi Jambi

\section{METODOLOGI PENELITIAN}

Penelitian ini dilakukan di Desa Mekar Jaya Kecamatan Betara Kabupaten Tanjung Jabung Barat Propinsi Jambi. Pemilihan Desa Mekar Jaya dengan alasan bahwa desa ini memiliki luas tanam dan produksi kopi terbesar di Kecamatan Betara. Jenis data yang digunakan yaitu data Cross Section dengan data berdasarkan skala pengukuran adalah data rasio dan data yang diambil berasal dari data primer dan data sekunder. Petani dan pedagang adalah sebagai sumber data primer, Sumber data sekunder dalam penelitian ini, diperoleh dari literaturliteratur dan instansi-instansi terkait. Dengan menggunakan metode survey, tehnik pengumpulan data secara observasi, wawancara dan pengisian kuisioner yang terpola dan terstruktur sesuai dengan kebutuhan akan data penelitian. 
Jurnal Media Agribisnis Vol. 4 No. 1 Tahun 2019 Hal 28 - 33

Media Komunikasi Hasil Penelitian Bidang Ilmu Agribisnis

ISSN print 2548-7027

ISSN online 2541-6898

Pada penelitian ini untuk di tahap petani digunakan metode sampel berdasarkan acak sederhana (simple random sampling), dengan metode undian, Untuk tahap pedagang digunakan metode Snowball sampling atau sampling bola salju. Data dianalisis secara deskriptif untuk mengetahui saluran tataniaga, serta untuk menghitung margin tataniaga masing-masing petani digunakan pencatatan yang secara sistematis marjin tataniaga dapat diketahui dengan rumus sebagai berikut: (Nasruddin, 1999)

$$
A G M=\frac{P s-P b}{V}
$$

Dimana :

$\begin{array}{llll}\text { AGM } & : & \text { Margin kotor rata-rata(Rp/Kg) } \\ \mathrm{P}_{\mathrm{s}} & : & \text { Nilai Penjualan }(\mathrm{Rp} / \text { Periode }) \\ \mathrm{P}_{\mathrm{b}} & : & \text { Nilai Pembelian(Rp/Periode }) \\ \mathrm{V} & : & \text { Volume barang dagangan }(\mathrm{Kg} / \text { Periode })\end{array}$

Untuk mengetahui keuntungan yang diterima maka digunakan rumus sebagai berikut: (Hamid, 1972).

Dimana :

$$
\pi=M-C
$$

$\pi \quad$ : Keuntungan $(\mathrm{Rp} / \mathrm{kg} /$ Periode $)$

M : Marjin kotor rata-rata $(\mathrm{Rp} / \mathrm{kg} /$ Periode)

C : Biaya $(\mathrm{Rp} / \mathrm{kg} /$ Periode $)$

\section{HASIL DAN PEMBAHASAN}

Saluran tataniaga adalah seperangkat organisasi yang saling bergantung yang terlibat dalam proses menyediakan produk atau layanan sehingga dapat digunakan atau dikonsumsi (Kotler dkk, 2005). Menurut Swasta (2008), Saluran pemasaran adalah saluran yang digunakan oleh produsen untuk menyalurkan barang tersebut dari produsen sampai ke konsumen atau pemakai industri. Dari hasil penelitian mengenai saluran tataniaga kopi yang dilakukan di Desa Mekar Jaya Kecamatan Betara, diketahui bahwa terdapat 1 pola saluran tataniaga kopi (Gambar 1). Saluran tataniaga tersebut dimulai dari petani kopi Desa Mekar Jaya yang menjual kopi langsung ke pedagang pengumpul yang ada di desa tersebut kemudian pedagang pengumul menjual hasil kopi kepada pengumpul besar (toke cina).

Pedagang pengumpul terdiri atas 2 orang masing-masing membeli kopi dari semua petani di daerah penelitian. Harga beli kopi pengumpul dari petani atau harga jual kopi petani adalah sebesar Rp. 40.000. Total petani sebanyak 48 orang, 24 petani menjual kopi kepada pengumpul 1 dan 24 petani menjual kepada pengumpul 2. Volume kopi yang diperjualbelikan berasal dari pengumpul 1 sebanyak $1.210 \mathrm{~kg}$ atau $(44,80 \%$ dari total produksi petani) sedangkan pengumpul 2 memperjualbelikan kopi sebanyak $1.490 .50 \mathrm{~kg}(55,19 \%$ dari total produksi petani). 
Jurnal Media Agribisnis Vol. 4 No. 1 Tahun 2019 Hal 28 - 33

Media Komunikasi Hasil Penelitian Bidang Ilmu Agribisnis

ISSN print 2548-7027

ISSN online 2541-6898

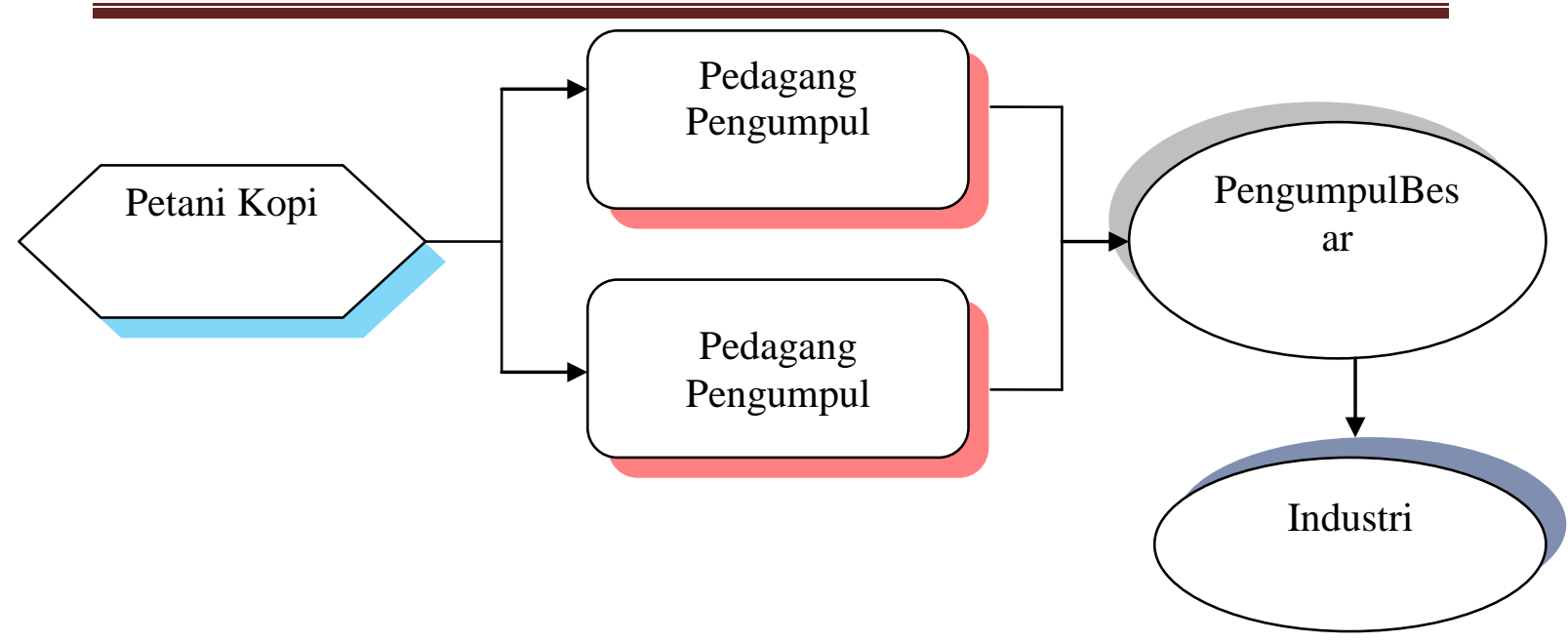

Gambar 1. Saluran Tataniaga Kopi di Desa Mekar Jaya Kecamatan Betara Kabupaten Tanjung Jabung Barat Tahun 2018

Pengumpul menjual kopi ke pengumpul besar (toke cina). Volume kopi yang dijual kepengumpul besar dari 2 orang sampel pengumpul sebanyak 2.700,50 kg dengan harga jual sebesar Rp. 43.000.

Margin tataniaga adalah selisih harga yang dibayarkan konsumen akhir dengan harga yang diterima petani (Daniel, M (2002). Selanjutnya Limbong (2010), mengartikan marjin pemasaran sebagai nilai dari jasa-jasa pelaksanaan dari kegiatan tataniaga mulai tingkat produsen hingga ke tingkat konsumen. Marjin tataniaga sering dipergunakan sebagai perbedaan antara harga diberbagai tingkat lembaga pemasaran di dalam sistem pemasaran. (Kohls, 2002). Analisis margin tataniaga dapat digunakan untuk mengetahui distribusi margin pemasaran yang terdiri dari biaya dan keuntungan dari setiap aktivitas lembaga tataniaga yang berperan aktif serta untuk mengetahui bagian harga (farmer share) yang diterima petani. Marjin tataniaga sering digunakan sebagai indikator dalam mengukur efisiensi saluran tataniaga.

Petani kopi merupakan petani yang melakukan kegiatan usahatani kopi. Total petani dalam penelitian ini sebanyak 48 orang. Dari total petani tersebut sebanyak 24 petani menjual kopi kepada pengumpul 1 dan 24 petani menjual kepada pengumpul 2. Produksi kopi yang dihasilkan petani selama proses produksi sebanyak $2,700.50 \mathrm{~kg}$. Kopi tersebut dijual ke 2 orang pengumpul dengan harga jual sebesar Rp. 40,000. Selain itu, petani tidak mengeluarkan biaya kirim kopi ke pengumpul karena pengumpul mengambil sendiri kopi ke petani.

Harga kopi ditingkat petani dalam penelitian ini berkisar antara Rp. 39.000 sampai Rp. 40.000. Harga jual kopi ditingkat petani mengalami perbedaan sesuai dengan kualitas kopi yang dijual kepada pengumpul dan harga ditentukan oleh pengumpul kopi di daerah penelitian.

Pedagang pengumpul pada penelitian ini sebanyak 2 orang. Pedagang pengumpul membeli kopi dari petani produsen kopi. Pengumpul 1 membeli kopi dari 24 orang petani kopi dan pengumpul 2 membeli kopi dari 24 petani. Volume kopi yang diperjualbelikan oleh pengumpul 1 adalah sebanyak $1,210 \mathrm{~kg}$ 
Jurnal Media Agribisnis Vol. 4 No. 1 Tahun 2019 Hal 28 - 33

Media Komunikasi Hasil Penelitian Bidang Ilmu Agribisnis

ISSN print 2548-7027 ISSN online 2541-6898

sedangkan pada pengumpul 2 volume kopi yang diperjualbelikan adalah sebanyak $1,490.50 \mathrm{~kg}$.

Total volume kopi yang diperjualbelikan oleh pedagang pengumpul sebesar $2.700,5 \mathrm{~kg}$. Margin kotor rata-rata pedagang pengumpul akibat selisih margin kopi dari petani sebesar Rp. 3.000, nilai ini didapatkan dari selisih nilai pembelian $(\mathrm{Pb})$ dan nilai penjualan (Ps) terhadap volume kopi yang diperjualbelikan. Ratarata keuntungan pedagang pengumpul sebesar Rp. 2.475 setelah dikurangkan dengan biaya yang dikeluarkan pedagang pengumpul rata-rata sebesar Rp. 525. Pengumpul dalam rantai tata niaga ini memiliki biaya produksi sebesar Rp. 700/kg untuk pengumpul 1 dan Rp. 350/kg untuk pengumpul 2. Masing-masing biaya produksi ini digunakan untuk transportasi yang terdiri atas transportasi penjemputan kopi di petani dan transportasi antar kopi ke pengumpul besar.

Pedagang pengumpul besar pada penelitian ini sebanyak 1 orang. Pedagang pengumpul besar membeli kopi dari pengumpul. Jumlah pengumpul yang menjual kopi ke pengumpul besar cukup banyak, akan tetapi yang di hitung dalam penelitian ini sebanyak 2 pengumpul. Volume kopi yang diperjualbelikan oleh pengumpul ke pengumpul besar dalam penelitian ini sebanyak $2.700,5 \mathrm{~kg}$. Harga beli kopi pengumpul besar atau harga jual pengumpul kecil ke pengumpul besar yakni Rp. 43.000. Harga kopi yang di jual oleh pengumpul besar ke pengusaha kopi di pulau jawa (industri) yakni sebesar Rp. 48.000.

Margin kotor rata-rata pedagang pengumpul akibat selisih margin kopi dari petani sebesar Rp. 5.000, nilai ini didapatkan dari selisih nilai pembelian $(\mathrm{Pb})$ sebesar Rp. 116,121,500.00 dan nilai penjualan (Ps) sebesar Rp. 129,624,000.00terhadap volume kopi yang diperjualbelikan.

\section{KESIMPULAN}

Berdasarkan hasil dan pembahasan maka dapat disimpulkan sebagai berikut :

1. Saluran tataniaga yang terbentuk pada penelitian ini adalah saluran tataniaga sederhana yaitu petani - pedagang pengumpul - pedagang pengumpul besar industri.

2. Rata-rata marjin tataniaga antara petani dan pengumpul sebesar Rp. 3000/kg, sedangkan marjin rata-rata antara pengumpul dengan pengumpul sebesar Rp. 5000/kg. Marjin tataniaga total dari marjin tataniaga satu (M1) dengan marjin tataniaga dua (M2) adalah Rp. 8000/kg.

\section{DAFTAR PUSTAKA}

Badan Pusat Statistik. 2018. Jambi dalam Angka 2018. Badan Pusat Statistik. Jambi

Badan Pusat Statistik. 2018. KabupatenTanjungJabung Barat Dalam Angka 2018. Badan Pusat Statistik KabupatenTanjungJabung Barat. BPS Kabupaten Tanjung Jabung Barat

Badan Pusat Statistik. 2018. Kecamatan Betara dalam Angka 2018. Badan Pusat StatistikKabupatenTanjungJabung Barat. BPS Kabupaten Tanjung Jabung Barat

BasuSwastha. 2008. ManejemenPemasaran Modern. (edisi 2), yogyakarta :Penerbit Liberty-Yogyakarta 
Jurnal Media Agribisnis Vol. 4 No. 1 Tahun 2019 Hal 28 - 33

Media Komunikasi Hasil Penelitian Bidang Ilmu Agribisnis

ISSN print 2548-7027

ISSN online 2541-6898

Daniel, M. 2002. PengantarEkonomi Pertanian. BumiAksara, Jakarta.

Direktorat Jendral Perkebunan. 2018. Statistik Perkebunan Indonesia 2015-2017

Kopi. Sekretariat Direktorat Jenderal Perkebunan, Direktorat Jenderal Perkebunan Kementerian Pertanian.

Hamid, Ak. 1972. Tataniaga Pertanian. Fakultas Pertanian Universitas Hasanuddin. Makasar.

Kohls, R. 2002. Marketing Of Agricultural Product. Ninth Edition. New Jersey. Prentice Hall.

Kotler, P. 2005. ManajemenPemasaran.Penerjemah : Hendra Teguh, Roni, A Rusli dan Benyamin Molan. Ed. 10. PT. Prenhalindo.Jakarta.

Limbong, 2010. Pengantar Tataniaga Pertanian. Jurusan Ilmu-ilmu Sosial Ekonomi Pertanian, Fakultas Pertanian. Institut Pertanian Bogor. Bogor

Nasaruddin, W. 1999. Tataniaga Pertanian. Cet 2. Universitas Terbuka. Jakarta. 